\title{
Study on the Relationship between Big Data and Consumer Finance in Guizhou Province
}

\author{
Fan Duan ${ }^{1,2,3}$ Hongmei Zhang ${ }^{1,2,3}$ Yingpeng Lai ${ }^{4}$ \\ ${ }^{1}$ Guizhou University of Finance and Economics, Institute of Finance \\ ${ }^{2}$ Guizhou Institution for Technology Innovation \& Entrepreneurship Investment \\ ${ }^{3}$ Guizhou Institute of Urban Economics and Development Guiyang Guizhou 550025, \\ China
}

\begin{abstract}
Consumer finance refers to the financial services of consumer finance companies, Banks, Internet e-commerce companies and stage shopping platforms to provide consumers with the purpose of consumption. Compared with traditional consumer finance, the innovation of the technology layer brought by Internet finance helps to reduce the information asymmetry between Banks and borrowers, which can help bank risk management. Under the new normal economy, consumption is one of the troika driving economic growth. Whether from the perspective of developing financial products or driving economic growth, developing consumer finance is of positive significance. This paper introduces the development of China's consumer finance policy and the environment, and through the analysis of typical cases, for scenario analysis of large data services ecological closedloop, credit, risk control and so on aspects of the influence of the Internet consumer finance and development trend.
\end{abstract}

Consumer finance; Big data; Credit reporting

\section{Keywords}

\section{贵州省大数据与消费金融的内在关系研究}

\author{
段凡 $1,2,3$ 张红梅 ${ }^{1,2,3}$ 赖应鹏 4 \\ 1 贵州财经大学, 金融学院 \\ 2 贵州科技创新创业投资研究院 \\ 3 贵州城镇经济与发展研究院, 贵州, 贵阳 550025 \\ ${ }^{4}$ 中国农业银行贵州省分行
}

摘要：消费金融是指消费金融公司、银行、互联网电商、分期购物平台向各阶层消费者提供 以消费为目的的贷款的金融服务方式。与传统消费金融相比，互联网金融带来技术层而的革 新, 有助于减轻银行与借款者的信息不对称问题，从而有助于银行风险管理。经济新常态 下，消费作为拉动经济增长的三驾马车之一。无论从开发金融产品的角度还是拉动经济增长 角度看，发展消费金融都具有积极意义。本文从介绍我国消费金融发展的政策和环境入手， 并通过分析典型案例, 分析大数据对于场景化服务生态闭环、征信、风控等方面对互联网消 费金融的影响以及发展趋势。

关键词：消费金融；大数据；征信 


\section{1. 引言}

大数据概念最初源 IT 技术不断进 步，IT 技术的不断进步使得全球数据 呈 “爆炸式”增长。而数据作为一种 新的能源，其潜在的巨大价值有待发 掘。而大数据与传统的数据分析的区 别是使用全量数据代替样本数据。随 着科技的发展我们不再受限与海量数 据难以储存, 全量数据运算速度的瓶 颈，使我们有机会用全量数据代替抽 样的样本, 并根据全量数据表现出的 特征作为我们分析的依据。大约从 2009 年始, “大数据”成为互联网信 息技术行业的流行词汇。事实上，大 数据产业是指建立在对互联网、物联 网、云计算等渠道广泛、大量数据资 源收集基础上的数据存储、价值提 炼、智能处理和分发的信息服务业。

\section{2. 贵州省大数据及消费金融现状}

\section{1. 贵州省大数据发展现状}

贵州省从数据存储起步, 发展数据 中心, 从政府数据的汇聚融通切入, 建 设统一的系统平台。贵州省先天的环境 优势能源优势, 结合贵州省政府通过政 ${ }^{1}$ 策推进大数据产业发展的先行优势, 先 行优势。先发声并且快赶路, 在先行先 试中贵州省在很多方面走在了国内的前 列。十个率先, 涵盖了理论研究、平台

作者简介: 张红梅, 教授、硕士生导师, 任职于贵州财经大学金融学院, 研究方 向：金融与区域发展、创业投资、风险分 析与管理。Email: 754560989@qq.com。

段凡, 男, 贵州财经大学金融学院研究生 硕士。贵州财经大学在读研究生, 研究方 向：金融与区域发展、创业投资、风险分 析与管理。Email: 372050817@qq.com。 赖应鹏, 男, 现就职于中国农业银行贵州 省分行公司大客户部任一部经理。Email: 7894859@qq.com。
搭建、基础设施建设、产业链构架、立 法保障、专业国际峰会及赛事等多个维 度。获批建设国家大数据综合试验区, 省政府数据开放平台上线运行，省、市 （州）两级 481 个运用系统迁入 “云上 贵州”。三大运营商、多个国家部委和 华为、阿里等多家顶级企业大数据中心 落地贵阳, 奠定贵州在中国大数据版图 上的执牛耳地位。贵阳观山湖区的贵州 金融城不仅聚集了一大批全国性金融机 构的大数据中心，还有全国第一家大数 据交易所落户。贵州的大数据集聚效应 令人刮目。

\section{2. 贵州省消费市场分析}

自 2011 年以来, 随着社会经济的 不断发展和政府的大力扶持, 贵州省 城乡常住居民人均可支配收入, 社会 消费品零售总额一直保持者稳定增长 的状态。在世界范围内经济普遍增长 放缓国内经济面临下行压力的形势 下，仍然保持在合理运行区间。但 是, 贵州省在全国范围内仍然属于欠 发达地区，第一社会消费品零售总额 增长趋势变换。第二, 可支配收入大 幅增长但是总量偏低。经济新常态 下, 海外市场需求疲软, 人民币升值 使出口压力巨大, 产业升级转型使投 资乏力, 拉动经济增长的三驾马车 中, 消费成为目前最重要的环节。

(如图 1 所示)

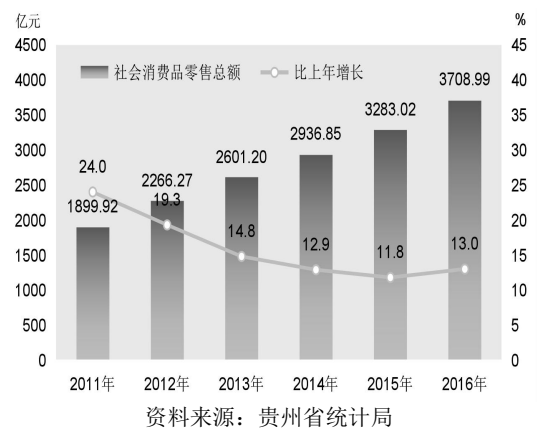

图 1 2011-2016 年社会消费品零售总额及其增长速度 


\section{3. 大数据技术与消费金融的案例分析}

\section{1. 电商巨头布局场景化服务}

电商巨头凭借其在资本上的优势, 近年来大肆在生活服务 020 领域内布 局，以阿里为例子，投资了分期购物平 台趣分期, 自有旅游平台阿里去啊, 投 资旅游网站穷游网，影音行业的优酷土 豆虾米音乐, 以及高德地图 UC 浏览 器。在各个领域拥有一定资源业务之间 的打通，能够有效连接消费金融的需求 场景布局生态圈闭环。在电商场景内, 在商城平台为用户提供㻌购服务; 在校 园场景内, 作为校园生态的衍生, 关注 大学生创业, 以及培训相关的消费金 融; 在旅游场景内与旅游网站合作, 为 用户提供消费信贷产品等等。而细分场 景下电商巨头可以根据对不同场景下对 客户多渠道、多维度的刻画更加深入的 了解消费者。再根据对消费者行为分 析、消费习惯、消费能力的掌握进行精 准推广营销。甚至可以创造符合消费者 消费偏好, 激发消费者购物需求的场 景, 进一步的刺激消费。

\section{2. 大数据下的消费金融的独特优势}

随着网络的普及, $\mathrm{PC}$ 端向移动端 迁移已完成, 全民进入移动互联网时 代。对于数据分析我们不再受限与海量 数据难以储存, 全量数据运算速度的瓶 颈, 使我们有机会用全量数据代替抽样 的样本, 并根据全量数据表现出的特征 作为我们分析的依据。大数据具有规模 性、高速性、多样性、而且无处不在等 全新特点, 具体地说, 是指需要通过快 速获取、处理、分析和提取有价值的、 海量、多样化的交易数据、交互数据为 基础, 大数据的核心价值就是资源优化 配置。而大数据正是这样一种独特的技 术, 通过全量的数据挖掘对全部样本进 行分析, 得出事情发展的客观事实, 准 确的反映事物发展的趋势, 此独特的功
能正是金融行业急需的独特技能。我一 直认为大数据的最大魅力在于开启了人 类的 “上帝视角” , 人类从一个前所未 有的角度俯瞰着这个世界, 知道全国乃 至全世界的商品流动情况, 知道每个商 圈的繁荣情况, 知道全球的航空业发展 状况等, 而这一切, 都可以作为我们判 断未来经济趋势的最重要根据, 这是人 类以前从未有过的预测能力。电商巨头 凭借在消费生态圈场景闭环的优势, 在 消费金融方面的全流程均可在其体系内 统一完成, 通过内部、外部统一作战。 第一, 经过多年经营, 积累了大量的活 跃用户，同时在各生活服务楼场景中大 量布局, 完善了生态体系。第二, 电商 拥有会员用户海量的交易数据, 基于大 数据风控模型, 电商相比传统金融机构 以更低的成本来度量用户的风险水平。

\section{4. 大数据金融的运行机理及机制}

\section{1. 大数据金融的运行机理}

大数据技术对于消费金融的核心价 值就是精准。第一，通过 “众包” 产生 和收集数据。而所谓的 “众包” 指的是 一个公司或机构把过去由员工执行的工 作任务, 以自由自愿的形式外包给非特 定的（而且通常是大型的）大众网络的 做法。大数据的 “海量数据” 就是由 “众包” 产生的。广义上, 用户的行为 数据, 各种传感器的数据, 也都是 “众 包” 的形式, 只要是由过去集中式的产 生模式扩散到分布式的模式, 都是众包 的形式。第二, 通过 “全量数据挖掘” 获知消费者的消费痛点, 消费习惯, 刺 激消费。随着科技的发展我们不再受限 与海量数据难以储存, 全量数据运算速 度的瓶颈, 使我们有机会用全量数据代 替抽样的样本, 并根据全量数据表现出 的特征作为我们分析的依据。我们再也 不用通过 “以管窥天” 的小格局来推测 全局, 而可以根据全场景闭环多渠道多 
维度的分析消费者的消费行为。这就是 大数据技术给消费金融带来的精准推广 能力, 我们获得了前所未有的获取准客 户的能力, 而且对于大型互联网公司来 说, 即使是 $\mathrm{PB}$ 级别的数据分析也是准 实时的, 我们下一个小时就能够得知上 一个小时的全量数据分析结果, 这样的 能力是前所未有的。

\section{2. 大数据金融的机制实施}

数据, 作为一种新的能源正在发生 巨变, 变革者我们的生产和生活。而如 果我们无视这些数据, 不能有效利用并 发掘它, 继而产生价值, 那么它同时也 会成为一场灾难。无序, 无结构的数据 犹如堆积如山的垃圾, 给企业国家带来 令人㕧舌的高额成本。当又一次科技浪 潮带给我们生活巨变的同时, 金融行业 作为资本市场的前端更不能闭门造车, 第一, 建立互联网思维, 发展互联网金 融, 传统的金融已经更不上现在人们快 节奏的生活节奏。包括向前几年的余额 宝, 和最近的花呗的迅速发展, 都告诉 我们传统的金融行业需要变革。第二, 加快速度收集客户的信息, 完善个人征 信制度, 以客户体验为中心, 收集客户 的消费习惯, 消费方式, 信用程度。阿 里云和腾讯以淘宝网和微信, $\mathrm{QQ}$ 已经在 收集大量的客户信息上走在了前端。虽 然现在已然追赶不上, 但是传统金融 业: 银行, 保险积累了大量的客户的有 效信息。信息的质量上比互联网起家的 阿里腾讯更高。第三, 数据就是新的能 源, 如何迎接新一轮的科技革命, 尽早 布置大数据战略, 就能抢占先机。从这 一点看, 招揽大数据相关的高端人才, 提前布局大数据更显得刻不容缓。

\section{5. 消费金融行业所面临的风险}

随着消费金融辐射人群扩大, 风 险水平也不断加大, 近年来我国消费 金融行业资产不良率加速上升, 虽然
仍低于日本和欧洲的不良率, 但我们 更要防微杜渐。消费金融金融机构应 当从用户全流程全面完善风控能力。 消费前, 对身份信息的有效性严格把 关; 消费中, 明确资金用途, 把握还 款进度, 对订单严格审查; 贷款中, 要建立用户信用评估模型, 评估用户 信用等级, 实行差异化利率政策; 同 时在贷后管理上, 也要做好客户的追 踪监控, 行为预测。对客户的逾期还 款做原因调查, 及时对消费贷款债权 转让, 规避风险。大数据成为资产、 行业垂直整合、各场景泛金融化造就 生态圈闭环成为商业发展主流趋势, 消费金融创造出新的商业模式, 塑造 新的经济形态, 创造新的经济生态空 间, 促进了消费, 拉动内需, 在经济 新常态下, 海外市场需求疲软, 人民 币升值使出口压力巨大, 产业升级转 型使投资乏力, 消费成为目前最重要 的环节, 大数据基因已经融入到消费 金融的技术结构之中。

\section{6. 消费金融的发展趋势}

消费金融与大数据将深度融合， 数据驱动消费金融创新发展。未来消 费金融将在产品、服务及风险管理方 面与互联网进行深度融合。第一产品 的互联网化, 面对广大的小额、分 散、无抵押无担保等特性, 对成本控 制要求较高。而花呗等消费金融产品 展现了强大的生命力, 受到了广大用 户的欢迎。第二服务的互联网化, 互 联网凭借各种创新将拓宽企业的服务 能力, 服务广度和深度, 提升服务效 率。第三风险管理的互联网化, 伴随 着互联网经济的发展以及对于线下经 济的渗透, 未来所有的数据都将是可 数据化, 可被记录的, 互联网将为消 费金融补全征信信息, 全面提升各类 机构的风险管理能力。 


\section{7. 贵州省发展大数据金融的优势}

首先，从国家政策上贵州省发展 大数据具有很大的优势, 获批建设国 家大数据综合试验区。贵州省生态环 境适宜, 夏季凉爽利于机房降低成 本。不处于地震带, 多山和喀斯特地 貌也为建立大数据中心提供了天然的 屏障。丰富的水煤资源成为大数据中 心的能源保障。贵州省处于西南地 区, 是我国经济发展的大后方, 不靠 江，不临海是我国扶贫攻坚的重中之 重, 也是全面脱贫的重心。随着国家 的支持力度不断加大, 贵州省的交通 结构不断改善。使贵州成为连接珠三 角与成渝经济带的交通枢纽, 也成为 了一带一路的重点区域。贵州省应该 抓住机遇, 紧跟大数据的科技浪潮。 建立大数据中心, 先行先做, 吸引人 才企业入驻, 发展大数据金融。

\section{参考文献}

[1] 梁丽萍吴芸粀杨营. 互联网进入大 数据时代畜牧业如何借力? [J]. 饲 料与畜牧, $2015(3): 7-7$.

[2] 陈浩. 基于 Hadoop 的微博用户影 响力排名算法研究 [D]. 华东理工 大学, 2014.

[3] 邸琳. 银泰百货集团发展战略研究 [D]. 燕山大学, 2014.

[4] 钟瑛张恒山. 大数据的缘起、冲击 及其应对 $[\mathrm{J}]$. 现代传播 (中国传媒 大学学报), 2013(7):110-115.

[5]杜梅萍. 把握我国经济发展的大逻 辑 [J]. 前线, 2015 (1):27-29.

[6] 孙克强范玮肖平陈涵骆祖春方维慰 丁敬文. “新常态” 下江苏农村服 务业发展分析一一基于典型乡镇的 情况调研 $[J]$. 金陵科技学院学报 (社会科学版), 2015 (1):7-11. 